\title{
Tingkat Kesuburan Perairan Kolong Pasca Galian Tambang Pasir Sidodadi, Pulau Sugi Bawah, Provinsi Kepulauan Riau
}

\section{Trophic Level on Abandoned Sand Mining Pit of Sidodadi, Sugi Bawah Island, Riau Islands Province}

\author{
Sunartri Agung*1, Tri Apriadi ${ }^{1}$, Winny Retna Melani ${ }^{1}$ \\ ${ }^{1}$ Jurusan Manajemen Sumberdaya Perairan, Fakultas Ilmu Kelautan dan Perikanan, \\ Universitas Maritim Raja Ali Haji, Kota Tanjungpinang, Kepulauan Riau-29125 \\ Korespondensi: tri.apriadi@umrah.ac.id
}

\begin{abstract}
ABSTRAK
Kolong Sidodadi merupakan genangan perairan yang terbentuk di lahan pasca tambang pasir darat di Pulau Sugi Bawah, tepatnya di Kampung Sidodadi, Kecamatan Moro, Kabupaten Karimun. Kolong ini dimanfaatkan sebagai sumber air baku oleh PDAM Tirta Karimun. Penelitian ini bertujuan untuk mengkaji kondisi parameter fisika, kimia, dan biologi serta tingkat kesuburan perairan Kolong Sidodadi, Kabupaten Karimun, Kepulauan Riau. Pengambilan sampel dilakukan secara random sampling sebanyak 30 titik sampling yang tersebar di Kolong Sidodadi. Parameter fisika, kimia, dan biologi perairan yang diukur yaitu suhu, kecerahan, pH, DO, nitrat, fosfat, dan klorofil-a. Kualitas perairan dianalisis berdasarkan kesesuaian baku mutu menurut Peraturan Pemerintah Republik Indonesia No. 82 Tahun 2001. Indeks kesuburan dihitung menggunakan metode Trophic Level Index (TLI). Hasil penelitian menunjukkan bahwa Kolong Sidodadi memiliki pH asam (rendah), konsentrasi nutrien N dan P tinggi, serta klorofil-a rendah. Nilai kesuburan berdasarkan indeks TLI berkisar 3,60-4,40 dengan rataan 4,00. Tingkat kesuburan perairan Kolong Sidodadi tergolong eutrofik (tinggi). Perlu menjadi perhatian terhadap nilai $\mathrm{pH}$ yang rendah karena air Kolong Sidodadi ini digunakan sebagai sumber air baku bagi PDAM Tirta Karimun. Selain itu, diperlukan kajian keanekaragaman dan kelimpahan fitoplankton sehingga dapat mengkonfrimasi konsentrasi klorofil-a yang menjadi komponen utama dalam penentuan tingkat kesuburan perairan.
\end{abstract}

Kata kunci: kesuburan perairan, klorofil-a, kolong, PDAM, TLI

\begin{abstract}
Sidodadi Pit is abandoned sand mining pond in Sidodadi Village, Sugi Bawah Island, Moro District, Karimun Regency. This pit is used as a source of raw water by Regional Drinking Water Company of Tirta Karimun. This study aimed to determine the physical, chemical, biological parameters and trophic level of Sidodadi Pit, Karimun Regency, Riau Islands. Samples were taken randomly as many as 30 sampling points in Sidodadi Pit. The physical, chemical and biological waters parameters measured were temperature, tranparancy, $\mathrm{pH}, \mathrm{DO}$, nitrate, phosphate, and chlorophyll-a. Water quality analyzed based on the requirement water quality standard by Indonesian Government Regulation No. 82 of 2001, while the trophic level analyzed based on the Trophic Level Index (TLI). The results showed that Sidodadi Pit had acidic $\mathrm{pH}$ (low), high nutrient concentrations of $N$ and $P$, and low chlorophyll-a. The trophic level of Sidodadi Pit based on the TLI were ranged from 3.60 to 4.40 with an average of 4.00 and classified as eutrophic (high). The low pH is necessary to be focused because it is used as raw water by Regional Drinking Water Company of Tirta Karimun. Futhermore, the study of phytoplankton diversity and abundance should be held to confirm the concentration of chlorophyll-a which is the main component in determining the level of trophic level index.
\end{abstract}

Keywords: abandoned pit, chlorophyll-a, Regional Drinking Water Company, TLI, trophic level 


\section{PENDAHULUAN}

Moro merupakan salah satu Kecamatan yang ada di Kabupaten Karimun, Provinsi Kepulauan Riau dengan luas wilayah $519,53 \mathrm{~km}^{2}$. Jumlah keseluruhan pulau di Kecamatan Moro ada 85 pulau, terdiri atas 19 pulau berpenghuni dan 66 pulau tidak berpenghuni. Kecamatan Moro memiliki jumlah penduduk 18.525 jiwa (BPS Kabupaten Karimun, 2019). Secara geografis wilayah Kecamatan Moro terdiri dari pulau-pulau yang terpisah. Pulau Sugi merupakan Pulau terbesar yang berada di Kecamatan Moro, diikuti Pulau Combol, Pulau Ciklim, dan lain-lain. Melani et al. (2020) menyatakan bahwa salah satu permasalahan di pulau kecil adalah minimnya ketersediaan air tawar, terutama sumber air baku. Hal ini juga yang terjadi di Kecamatan Moro. Salah satu upaya untuk memenuhi kebutuhan sumber air tawar bagi masyarakat di Kecamatan Moro yaitu dengan memanfaatkan air tawar di cekungan bekas galian pasir darat (kolong).

Wardoyo dan Ismail (1998) menjelaskan bahwa kolong merupakan genangan air yang terbentuk dari lahan bekas penambangan. Sumber air kolong umumnya berasal dari air hujan dan limpasan air permukaan (surface run off). Kecamatan Moro memiliki dua kolong (warga setempat menyebutnya waduk) yaitu, Kolong Sidodadi dan Sidomoro (Bapelitbang Karimun, 2018). Kolong Sidodadi yang terletak di Pulau Sugi Bawah, sejak tahun 2002 diperuntukkan sebagai sumber air baku bagi PDAM Tirta Karimun. Kolong ini memiliki luas yaitu 2,50 ha, kedalaman $\pm 4-5 \mathrm{~m}$ (tengah kolong) dan $\pm 1-2 \mathrm{~m}$ (tepian kolong), dan volume air normal $\left(100.000 \mathrm{~m}^{3}\right.$ ). Badan air Kolong Sidodadi sangat dipengaruhi oleh dampak aktivitas di sekeliling kolong (hutan, lahan tanah terbuka) yang diduga memberi sumbangsih run off terhadap kawasan kolong tersebut. Sebagai sebuah ekosistem perairan tergenang, dinamika parameter fisika, kimia, dan biologi sangat berpengaruh terhadap kehidupan biota, kesuburan perairan, serta produktivitas perairan kolong tersebut.

Kesuburan perairan adalah kapasitas atau kemampuan badan air dalam menyediakan nutrien yang sesuai bagi kehidupan fitoplankton sehingga dapat menghasilkan produktivitas primer yang optimum. Perairan yang subur mengandung banyak nutrien yang menunjang kehidupan organisme autotrofik, terutama dalam produksi primer oleh fitoplankton dan alga (Asriyana dan Yuliana, 2012). Kesuburan perairan biasanya dihubungkan dengan kosentrasi nutrien dalam badan perairan. Tinggi rendahnya kandungan klorofil-a sangat erat hubungannya dengan pasokan nutrien berasal dari 
darat yang masuk ke badan perairan (allochthonous) serta nutrien yang memang berada di perairan (autoochthonous) (Bertilsson dan Jones Jr, 2003; Peterson et al., 2003). Saat konsentrasi nutrien terlalu tinggi, maka akan terjadi peristiwa eutrofikasi (Ryding dan Rast, 1989). Hal inilah sangat dikhawatirkan apabila terjadi di perairan tergenang khususnya kolong, mengingat di perairan tergenang laju pembilasan air sangat kecil atau bahkan tidak ada sama sekali (Pratiwi et al., 2018; Pratiwi et al., 2010).

Berdasarkan hal tersebut, kondisi tingkat kesuburan suatu kawasan kolong merupakan faktor penting yang harus diperhatikan demi mendukung pengelolaan kolong sesuai peruntukkannya. Beberapa kajian telah dilakukan untuk mengetahui kondisi biolimnologi dan tingkat kesuburan di beberapa kolong pasca tambang antara lain kolong tambang pasir di Sukabumi (Octorina et al., 2017) serta Bekasi dan Tangerang (Krismono et al., 1998), kolong tambang timah di Bangka (Henny dan Susanti, 2009; Henny 2011), kolong tambang intan di Banjarbaru Kalimantan Selatan (Ropi'ah et al., 2017), serta kolong tambang bauksit di Kota Tanjungpinang (Apriadi et al., 2019). Kajian mengenai tingkat kesuburan perairan Kolong Sidodadi belum pernah dilaporkan. Oleh karena itu, penelitian ini dilakukan dengan tujuan untuk mengkaji kondisi parameter fisika, kimia, dan biologi serta tingkat kesuburan perairan Kolong Sidodadi, Kecamatan Moro, Kabupaten Karimun, Kepulauan Riau.

\section{METODE}

\section{Waktu dan Tempat Penelitian}

Penelitian ini dilaksanakan pada bulan Maret 2020, berlokasi di Kolong Sidodadi, Kabupaten Karimun (Gambar 1). Sampel diambil pada 30 titik sampling yang tersebar secara acak di seluruh area Kolong Sidodadi.

\section{Prosedur Penelitian}

Parameter perairan seperti suhu, $\mathrm{pH}$, dan DO diukur insitu pada 30 titik sampling yang ada menggunakan Multitester, sedangkan kecerahan diukur menggunakan Secchi disk. Pengulangan dilakukan sebanyak tiga kali pada setiap titik sampling. Sampel air untuk keperluan analisis nitrat, fosfat, dan klorofil diambil menggunakan Van Dorn water sampler berukuran $3 \mathrm{~L}$. Sampel air untuk keperluan analisis nitrat dan fosfat diambil secara komposit dari permukaan, kolom, dan dekat dasar perairan. Sampel air untuk klorofil-a diambil di kedalaman eufotik (berdasarkan nilai kecerahan perairan). 
Analisis nitrat dan fosfat menggunakan metode kolorimetri, sedangkan analisis konsentrasi klorofil-a menggunakan metode spektrofotometri (APHA, 2017).
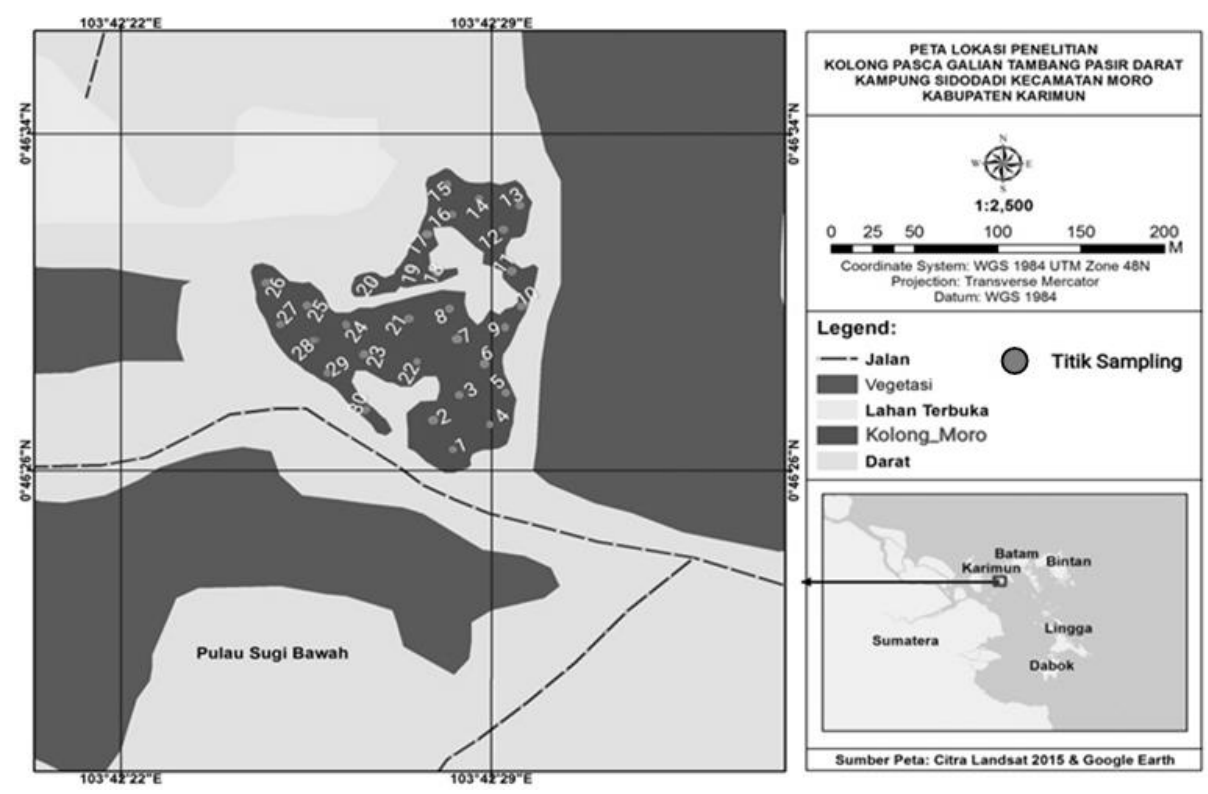

Gambar 1. Peta Lokasi Penelitian

\section{Analisis Data}

Data parameter fisika, kimia, dan biologi perairan dianalisis berdasarkan kesesuaian baku mutu menurut Peraturan Pemerintah Republik Indonesia No. 82 Tahun 2001 tentang pengelolaan kualitas air dan pengendalian pencemaran air (Kelas II) untuk mengetahui status mutu perairan kolong pasca galian tambang pasir darat di Sidodadi Kecamatan Moro.

Status kesuburan Kolong Sidodadi dihitung menggunakan metode Trophic Level Index (TLI) (Burns 2005). Nilai tingkat kesuburan berdasarkan kisaran TLI rata-rata dapat dilihat pada Tabel 1. Secara matematis nilai TLI dihitung dengan menggunakan persamaan sebagai berikut.

$$
\begin{aligned}
& \mathrm{TLI}_{\mathrm{chl}}=2,22+2,54 \log (\mathrm{Chl}) \\
& \mathrm{TLI}_{\mathrm{s}}=5,10+2,60 \log \left(\frac{1}{\mathrm{~s}}-\frac{1}{40}\right) \\
& \mathrm{TLI}_{\mathrm{TP}}=0,218+2,92 \log (\mathrm{TP}) \\
& \mathrm{TLI}_{\mathrm{TN}}=-3,61+3,01 \log (\mathrm{TN}) \\
& \text { TLI rata-rata }=\frac{\text { TLIchl }+ \text { TLIs }+ \text { TLIt }+ \text { TLIt } n}{4}
\end{aligned}
$$

Keterangan:

$\mathrm{TLI}_{\mathrm{chl}}=$ Nilai TLI untuk Klorofil-a $\left(\mathrm{mg} / \mathrm{m}^{3}\right)$ 
TLI $_{\mathrm{s}} \quad=$ Nilai TLI untuk Kedalaman secchi $\operatorname{disk}(\mathrm{m})$

TLI TP = Nilai TLI untuk total fosfat $\left(\mathrm{mg} / \mathrm{m}^{3}\right)$

$\mathrm{TLI}_{\mathrm{TN}}=$ Nilai TLI untuk total nitrogen $\left(\mathrm{mg} / \mathrm{m}^{3}\right)$

Tabel 1. Tingkat kesuburan perairan berdasarkan hasil penghitungan TLI (Pavluk dan Vaate, 2017)

\begin{tabular}{|c|c|c|c|c|c|c|}
\hline $\begin{array}{l}\text { Status tingkat } \\
\text { trofik }\end{array}$ & $\begin{array}{c}\text { Kategori } \\
\text { pengkayaan } \\
\text { nutrien }\end{array}$ & TLI & $\begin{array}{c}\text { Klorofil-a } \\
\left(\mathrm{mg} / \mathrm{m}^{3}\right)\end{array}$ & $\begin{array}{c}\text { Kecerahan } \\
\text { (m) }\end{array}$ & $\begin{array}{c}\text { Total Fosfat } \\
\left(\mathrm{mg} / \mathrm{m}^{3}\right)\end{array}$ & $\begin{array}{c}\text { Total } \\
\text { nitrogen } \\
\left(\mathrm{mg} / \mathrm{m}^{3}\right)\end{array}$ \\
\hline $\begin{array}{l}\text { Ultra mikro- } \\
\text { trofik }\end{array}$ & Alami & $0,0-1,0$ & $<0,33$ & $>25$ & $<1,8$ & $<34$ \\
\hline Mikrotrofik & $\begin{array}{l}\text { Sangat } \\
\text { Rendah }\end{array}$ & $1,01-2,0$ & $0,33-0,82$ & $25-15$ & $1,8-4,1$ & $34-73$ \\
\hline Oligotrofik & Rendah & $2,01-3,0$ & $0,82-2,0$ & $15-7$ & $4,1-9,0$ & $73-157$ \\
\hline Mesotrofik & Sedang & $3,01-4.0$ & $2,0-5,0$ & $7,0-2,8$ & $9-20$ & $157-337$ \\
\hline Eutrofik & Tinggi & $4,01-5,0$ & $5,0-12,0$ & $2,8-1,1$ & $20-43$ & $337-725$ \\
\hline Supertrofik & Sangat Tinggi & $5,01-6,0$ & $12,0-31,0$ & $1,1-0,4$ & $43-96$ & $\begin{array}{l}725- \\
1558\end{array}$ \\
\hline Hipertrofik & Jenuh & $>6,01$ & $>31$ & $<0,4$ & $>96$ & $>1558$ \\
\hline
\end{tabular}

\section{HASIL DAN PEMBAHASAN}

\section{Kondisi Parameter Fisika, Kimia, dan Biologi Perairan Kolong Sidodadi}

Parameter fisika, kimia, dan biologi perairan Kolong Sidodadi secara umum masih memenuhi baku mutu perairan, kecuali nilai $\mathrm{pH}$ dan konsentrasi fosfat (Tabel 2). Nilai rataan $\mathrm{pH}$ di Kolong Sidodadi sebesar 4,86, sehingga tergolong asam. Nilai ini masih jauh dari standar kelayakan hidup biota yaitu 6-9. Rendahnya nilai pH di Kolong Sidodadi diduga disebabkan oleh faktor geologi dan proses biologis yang terjadi di kolong tersebut. Hanny dan Susanti (2009) melaporkan bahwa kolong bekas tambang timah mempunyai kisaran $\mathrm{pH}$ sebesar 2,8-7,3. Nilai $\mathrm{pH}$ air kolong yang tergolong asam juga dijumpai pada kolong tambang timah (Hanny 2011) serta kolong tambang bauksit (Apriadi dan Ashari, 2018; Putra et al., 2018; Apriadi et al., 2019). Menurut Hanny (2011), kolong baru/muda yang pada batuan/material geologinya didominasi dari mineral kaolin umumnya mempunyai kisaran $\mathrm{pH}$ 4,5-6,0, sedangkan kolong baru/muda yang batuan/material geologinya didominasi oleh mineral pirit mempunyai kisaran $\mathrm{pH}$ 2,5-3,5. Kolong tua yang berumur $>10$ tahun mempunyai $\mathrm{pH}<5$ seperti pada kolongkolong dengan mineral dasar pembentuk kolong yang didominansi oleh pirit. 
Konsentrasi rata-rata nilai fosfat di perairan Kolong Sidodadi yaitu 0,221 mg/L. Konsentrasi fosfat pada kolong ini sudah melebihi baku mutu yang dipersyaratkan untuk air minum dalam Peraturan Pemerintah No 82 Tahun 2001(Kelas II) yang mensyaratkan nilai fosfat maksimal $0,200 \mathrm{mg} / \mathrm{L}$. Jika dilihat dari nilai fosfat pada lokasi penelitian ini termasuk tinggi (eutrofik). Selanjutnya berdasarkan Mustofa (2015), nilai fosfat diatas $1 \mathrm{mg} / \mathrm{L}$ termasuk pada perairan eutrofik dengan kesuburan tinggi.Wetzel (1970) juga berpendapat bahwa kadar fosfat 0,03-0,1 mg/L merupakan perairan yang eutrofik.

Tabel 2. Hasil Pengukuran Parameter Kualitas Perairan Kolong Sidodadi

\begin{tabular}{cccc}
\hline No & Parameter & Rataan & Baku Mutu* \\
\hline 1. & Suhu $\left({ }^{0} \mathrm{C}\right)$ & $32,5 \pm 0,43$ & Deviasi 3 \\
2. & Kecerahan $(\mathrm{m})$ & $2,49 \pm 0,15$ & - \\
3. & $\mathrm{pH}$ & $4,86 \pm 0,14$ & $6-9$ \\
4. & $\mathrm{DO}(\mathrm{mg} / \mathrm{L})$ & $5,90 \pm 0,36$ & 4 \\
5. & Nitrat $(\mathrm{mg} / \mathrm{L})$ & $6,78 \pm 4,59$ & 10 \\
6. & Fosfat $(\mathrm{mg} / \mathrm{L})$ & $0,22 \pm 0,14$ & 0,2 \\
7. & Klorofil-a $\left(\mathrm{mg} / \mathrm{m}^{3}\right)$ & $0,023 \pm 0,002$ & - \\
\hline
\end{tabular}

*Baku Mutu Berdasarkan PP 82 Tahun 2001 Kelas II

Sebaran konsentrasi klorofil-a menentukan tingkat kesuburan suatu perairan. Kandungan klorofil-a pada Kolong Sidodadi Kecamatan memiliki rata-rata 0,023 $\mathrm{mg} / \mathrm{m}^{3}$. Bila mengacu pada Wetzel (1970), konsentrasi klorofil <4 mg/m mengindikasikan perairan yang dengan kesuburannya yang rendah (oligotrofik). Menurut Agustina et al. (2016), nilai klorofil-a ini berkaitan dengan intensitas cahaya matahari yang digunakan oleh fitoplankton untuk melakukan proses fotosintesis dan ketersedian nutrien di perairan. Jika dibandingkan dengan penelitian Octorina et al. (2017), klorofil-a yang terdapat di genangan bekas galian pasir di Sukabumi memperoleh hasil klorofil-a yang tinggi yaitu $28,86 \mathrm{mg} / \mathrm{m}^{3}$. Tingginya klrofil-a di perairan tersebut dikarenakan sumber air yang masuk ke dalam perairan berupa limbah rumah tangga, limbah pertanian, dan air hujan merupakan penyumbang beban organik dan anorganik bagi perairan.

\section{Kesuburan Peraian Kolong Sidodadi}

Nitrat, fosfat, kecerahan dan klorofil- $a$, merupakan parameter kunci dalam penentuan kriteria tingkat kesuburan perairan. Berdasarkan hasil analisis tingkat kesuburan, tingkat kesuburan perairan Kolong Sidodadi berkisar 3,7-4,5 dengan rata- 
rata yaitu 4,12. Berdasarkan kriteria TLI, kesuburan perairan Kolong Sidodadi tergolong tinggi (eutrofik). Hal ini diduga disebabkan tingginya konsentrasi nutrien (nitrat dan fosfat).

Kandungan nitrat rata-rata setiap stasiun tertinggi terdapat di titik $(10,11,12)$ yang berada di lekukan kolong dengan nilai rata-rata $11,6 \mathrm{mg} / \mathrm{L}$ selanjutnya pada titik $(22,23,24)$ terdapat di samping badan kolong dengan nilai rata-rata $17,5 \mathrm{mg} / \mathrm{L}$. Tingginya kadar nitrat tersebut diduga adanya masukan zat hara dari aktivitas luar (hutan dan lahan tanah terbuka). Konsentrasi fosfat tertinggi terdapat pada titik 1,2,3 yaitu pada tempat pengambilan air baku PDAM dengan nilai rata-rata $0,41 \mathrm{mg} / \mathrm{L}$ selanjutnya pada titik 28,29,30 terdapat pada lekukan kolong dengan nilai rata-rata 0,49 mg/L. Menurut Rizal et al. (2017), tingginya kadar fosfor di perairan dapat berasal dari pengikisan bebatuan yang kemudian mengendap. Endapan-endapan tersebut perlahanlahan mengalami pengikisan dan melepaskan ion-ion fosfat ke perairan.

Nitrat dan fosfat merupakan unsur hara yang esensial bagi tumbuhan tingkat tinggi dan algae. Semakin lama waktu penggenangan, maka semakin banyak pula akumulasi bahan organik dan unsur hara pada perairan kolong. Kolong Sidodadi Kecamatan Moro memiliki umur kolong yaitu 18 tahun. Berdasarkan waktu pengenangan, kolong ini tergolong kolong tua (Wardoyo dan Ismail, 1998; Puspita et al, 2005) . Menurut Katnner et al. (2000), pada beberapa tahun pertama sejak penggenangan, umumnya kolong bekas galian tambang masih berstatus oligotrofik (tingkat kesuburan rendah). Hal ini sesuai dengan hasil penelitian Apriadi et al. (2019), bahwa kolong pasca tambang bauksit dengan waktu penggenangan $<5$ tahun memiliki tingkat kesuburan rendah (oligotrofik). Seiring berjalannya waktu, kolong yang mendapatkan tekanan antropogenik kemungkinan status trofiknya akan berubah. Perubahan status perairan dipengaruhi oleh umur, hidromorfometri, batasan unsur hara, dan produksi biomassa (Octorina et al., 2017).

Kadar nutrien di perairan Kolong Sidodadi yang tinggi diduga disebabkan oleh run off dari lahan di sekitar kolong yang selanjutnya terakumulasi. Salah satu sumber air bagi kolong adalah infiltrasi air tanah, namun input dari air limpasan di sekitar kolong dan air hujan diduga memberikan pengaruh pada perubahan sifat fisika dan kimia perairan tersebut (Brooks et al., 2003). Pengikisan batuan/sedimen yang terjadi secara alami maupun tidak alami (aktivitas manusia) dapat meningkatkan kadar nutrien di kolong air tersebut. 
Nitrogen dan fosfat hasil dekomposisi dapat menjadi penyebab terjadinya eutrofikasi. Menurut Zulfia dan Aisyah (2013), berdasarkan hasil analisis hubungan antara kandungan nitrat dan fosfat terhadap klorofil-a terlihat bahwa kandungan klorofil-a pada perairan meningkat seiring dengan peningkatan kandungan nitrat dan fosfat pada perairan. Namun berbanding terbalik dengan penelitian ini dikarenakan pada Kolong Sidodadi kecamatan memiliki kandungan klorofil-a yang tergolong rendah (oligotrofik). Klorofil-a yang rendah mengindikasikan kelimpahan fitoplankton sedikit. Hal ini diduga erat kaitannya dengan $\mathrm{pH}$ perairan yang rendah, sehingga dapat mengganggu pertumbuhan fitoplankton. Sesuai pernyataan Simanjuntak (2007)) bahwa pada saat $\mathrm{pH}$ asam, kelimpahan fitoplankton relatif kecil.

\section{KESIMPULAN}

Perairan Kolong Sidodadi memiliki pH rendah, konsentrasi nutrien ( $\mathrm{N}$ dan $\mathrm{P}$ ) tinggi, dan klorofil-a yang rendah. Tingkat kesuburan perairan Kolong Sidodadi Kecamatan tergolong tinggi (eutrofik). Kesuburan yang tinggi disebabkan tingginya konsentrasi nutrien di perairan. Perlu menjadi perhatian terhadap nilai $\mathrm{pH}$ yang rendah karena air Kolong Sidodadi ini digunakan sebagai sumber air baku bagi PDAM Tirta Karimun. Selain itu, diperlukan kajian keanekaragaman dan kelimpahan fitoplankton sehingga dapat mengkonfrimasi konsentrasi klorofil-a yang menjadi komponen utama dalam penentuan tingkat kesuburan perairan.

\section{DAFTAR PUSTAKA}

Agustina, S., Musman, M., Ishaq, M. 2016. "Status Klorofil-a di Perairan Teluk Pria Laot Sabang, Provinsi Aceh". Jurnal Ilmu-ilmu Perairan, Pesisir dan Perikanan, 6(3): 182-187.

[APHA] American Public Health Association. 2017. Standard Methods for the Examination of Water and Wastewater, $23^{\text {nd }}$ Edition. Maryland: United Book Press Inc.

Apriadi, T., dan Ashari, I.H. 2018. "Struktur Komunitas Fitoplankton pada Kolong Pengendapan Limbah Tailing Bauksit di Senggarang, Tanjungpinang". Majalah Ilmiah Biologi Biosfera - A Scientific Journal, 35(3): 145-152.

Apriadi, T., Putra, R.D., dan Idris, F. 2019. "Produktivitas Primer Perairan Kolong Bekas Tambang Bauksit di Kota Tanjungpinang, Kepulauan Riau”. Oseanologi dan Limnologi di Indonesia, 4(2): 113-121.

Asriyana dan Yuliana. 2012. Produktivitas Perairan. Bumi Aksara: Jakarta. 
[Bapelitbang Karimun] Badan Perencanaan Penelitian dan Pengembangan Kabupaten Karimun. 2018. Kajian Neraca Sumberdaya Air Permukaan Kabupaten Karimun Provinsi Kepulauan Riau. Karimun.

Bertilsson, S., dan Jones Jr, J.B. 2003. Supply of Dissolved Organic Matter to Aquatic Ecosystems: Autochthonous Sources. Editors: Findlay SEG, Sinsabaugh RL. Aquatic Ecosystem: Interactivity of Dissolved Organic Matter. USA: Academic Press, Elsevier Science.

[BPS Kabupaten Karimun] Badan Pusat Statistik Kabupaten Karimun. 2019. Kabupaten Karimun dalam Angka. Karimun: BPS Kabupaten Karimun.

Brooks, F.W.B., Lind, L.D., and Lind, O.T. 2003. "Seasonal and Spatial Variation in Algal Growth Potential and Growth-Limiting Nutrients in a Shallow Endorheic Lake: Lake Patzcuaro (Mexico)". Lakes \& Reservoirs: Research and Management, 8(2): 83-93.

Burns, N., McIntosh, J., and Scholes, P. 2005. "Strategies for Managing the Lakes of the Rotura District, New Zealand". Lake and Reservoir Management, 21(1): 61-72.

Henny C., dan Susanti, E. 2009. "Karakteristik Limnologis Kolong Bekas Tambang Timah di Pulau Bangka". LIMNOTEK, XVI(2): 119-131.

Henny, C. 2011. "Kolong Bekas Tambang Timah di Pulau Bangka: Permasalahan Kualitas Air dan Alternatif Solusi untuk Pemanfaatannya". Oseanologi dan Limnologi di Indonesia, 37(1): 119-138.

Kattner, E., Schwars, D., and Maier, G. 2000. "Eutrophication of Gravel Pit Lake which are Situated in Close Vicinity to the River Donau: Water and Nutrient Transport". Limnologica-Ecology and Management of Inland Waters, 30(3): 261-270.

Krismono, A.S.N., Nuroniah, S., dan Kartamiharja, E.S. 1998. "Kondisi Biolimnologi Sumberdaya Perairan Kolong Bekas Galian Pasir di Jawa Barat dan Kesesuaiannya Bagi Budidaya Perikanan”. Jurnal Penelitian Perikanan Indonesia, IV(1): 13-35.

Melani, W.R., Apriadi, T., Lestari, F., Saputra, Y.O., Hasan, A., Mawaddah, M.A.R., dan Fatmayanti, N. 2020. "Keanekaragaman Makrofita dan Fitoplankton di Waduk Gesek, Pulau Bintan, Kepulauan Riau”. LIMNOTEK, 27(1): 1-12.

Mustofa, A. 2015. "Kandungan Nitrat dan Fosfat Sebagai Faktor Tingkat Kesuburan Perairan Pantai". Jurnal DISPOTEK, 6(1): 13-19.

Octorina, P., MZ, N., Kustiawan, B., dan Nurbaeti, N. 2017. "Potensi Situ Bekas Galian Pasir Untuk Usaha Perikanan Sistem Culture Based Fisheries (CBF) dan Keramba Jaring Apung (KJA)". LIMNOTEK, 24(1): 44-51.

Pavluk, T., dan Vaate. 2017. Trophic Index Efficiency. Reference Module in Earth Systems and Environmental Sciences, USA: Elsevier Science. 
Peraturan Pemerintah No. 82 Tahun 2001. Pengelolaan Kualitas Air dan Pengendalian Pencemaran Air.

Peterson, J.A.A., McDowell, W.H., and Neff, J.C. 2003. Sources, Production, and Regulation of Allochthonous Dissolved Organic Matter Inputs to Surface Waters. Editors: Findlay SEG, Sinsabaugh RL. Aquatic Ecosystem: Interactivity of Dissolved Organic Matter. USA: Academic Press, Elsevier Science.

Pratiwi, N.T.M., Krisanti, M., Hariyadi, S., Wardiatno, Y., Effendi, H., Ayu, I.P., dan Iswantari, A. 2018. Buku Ajar Limnologi Pengantar. Bogor: IPB Press.

Pratiwi, N.T.M., Krisanti, M., dan Maryanto, I. 2010. Indikator kerusakan ekosistem perairan darat. Editor Musluhidin, Nooryanto B, Harmono S. Jakarta: Kementerian Lingkungan Hidup.

Puspita, L., Ratnawati, E., Suryadiputra, I.N.N., dan Meutia, A.A. 2005. Lahan Basah Buatan di Indonesia. Bogor: Wetlands International -Indonesia Programme.

Putra, R.D., Apriadi, T., Suryanti, A., Irawan, H., Raja'i, T.S., Yulianto, T., Putra, W.K.A., and Koenawan, C.J. 2018. "Preliminary Study of Heavy Metal (Zn, Pb, Cr, $\mathrm{As}, \mathrm{Cu}, \mathrm{Cd})$ Contaminations on Different Soil Level From Post-Mining Bauxite Production for Aquaculture". E3S Web of Conferences 47, 02008. SCiFiMaS.

Rizal, A.C., Yudi, N.I., Eddy, A., dan Lintang, P. 2017. "Pendekatan status nutrien pada sedimen untuk mengukur struktur komunitas makrozoobentos di wilayah muara sungai dan Pesisir Pantai Rancabuaya, Kabupaten Garut”. Jurnal Perikanan dan Kelautan, 7 (2): 7-16.

Ropi'ah, Asmawi, S., dan Arifin, P. 2017. "Plankton sebagai Bioindikator Kesuburan Kolong Kecamatan Cempaka Kota Banjarbaru Provinsi Kalimantan Selatan". Aquatic, 1(2): 99-118.

Ryding, S.O., dan Rast, W. 1989. The Control of Eutrophication of Lakes and Reservoirs. Paris: UNESCO paris \& The Parthenon Publishing Group.

Simajuntak, M. 2007. "Kadar Fosfat, Nitrat, dan Silikat di Teluk Jakarta". Jurnal Perikanan, IX(2): 274-284.

Wardoyo, S.E., dan Ismail, W. 1998. “Aspek Fisika Kimia dan Biologi Kolong-Kolong di Pulau Bangka untuk Pengembangan Perikanan”. Jurnal Penelitian Perikanan Indonesia, 4 (2): 75-85.

Wetzel, R.G. 1970. "Recent and postglacial Production Rates of a Mart Lake". Limnology Oceanography, 15(4): 491-503.

Zulfia, N., dan Aisyah. 2013. "Status Trofik Perairan Rawa Pening ditinjau dari Kandungan Unsur Hara $\left(\mathrm{NO}_{3}\right.$ dan $\left.\mathrm{PO}_{4}\right)$ serta Klorofil-a”. Jurnal BAWAL, 5(3): 189199. 